\title{
Lesson Plans: Format and Use During Classroom Instruction
}

\author{
Tiffany M. Shimmel, Lynn Columba \\ Lehigh University, Bethlehem, USA
}

\begin{abstract}
The purpose of this study is to determine the lesson plan format, which the in-service teachers are using to develop their lesson plans, and how they are using their lesson plans during classroom instruction. The participants are in-service secondary teachers at a public high school in the Northeast United States. They represent a variety of subjects taught, years of experience, and education levels. The study includes three instruments for data collection: a nine-question survey, a four-question interview, and lesson plans from various teachers at the high school. These instruments were used to ascertain trends in the lesson planning process and format among the faculty at this high school. The data identify four elements of lesson plans that are crucial to a successful planning process: objectives, questions to ask students, materials, and an explanation of the warm-up activity. All of these elements share a common theme: practicality. When teachers include these things, they are the most useful during classroom instruction. This study acts as a springboard to further comparative studies, investigations of alternative methods of planning, and research into the impact of higher education on future teachers.
\end{abstract}

Keywords: lesson planning, lesson plan format, secondary in-service teachers

\section{Introduction}

The lesson plan is embedded into formal education in such a way that every educator has the ability to sit down and write a lesson plan. However, there is little consensus among professionals about what elements need to be present in a lesson plan to make it most effective. Similarly, the purpose of a lesson plan varies greatly among educators, subject areas, schools, districts, and states.

A lesson plan is a resource for the instructor that indicates what and how material will be taught successfully during class time (Milkova, 2014). With this definition in mind, a preliminary search for existing lesson plans in the current research uncovered just over fifty different formats from a combination of recently published peer reviewed articles and books on the subject. This variety of lesson plan formats and elements leads to the question, which is the optimal format to use during class. Therefore, this study explores the most frequently used format of the lesson plan in order to guide educators for practical and successful implementation in the classroom.

A well-constructed lesson plan has the power to offer teachers a better look at their classroom, a new understanding of student needs, more opportunities to collaborate, the room to try new teaching strategies, a time to hone their professional skills, and a greater sense of confidence in the classroom (Kubilinskiene \& Dagiene, 2010). Gershon (2013) added that good planning maximizes lesson time. Magyar (2013) stated that a teacher must plan additional activities for their students, if there is extra time at the end of a lesson in order to

Tiffany M. Shimmel, M. Ed., graduate student, College of Education, Lehigh University. Lynn Columba, Ed.D., associate professor, College of Education, Lehigh University. 
not only maximize the time, but also the learning potential of each class. Other research noted the practical benefits of lesson plans: 1 . Inform a sequence of content to be covered; 2. Allow administrators to account for teacher professionalism; and 3. Provide substitute teachers with necessary information (Dunn et al., 2010). Lyons (1992) offered a different perspective, suggesting there are many successful instructional methods and techniques. Therefore, one can effectively stray from the traditional lecture-centered lesson plan.

However, lesson plans also have the ability to impede learning if not properly structured (Dunn et al., 2010). Dunn et al. (2010) noted the limitations of a lesson plan because the plan itself cannot provide information about the level of student engagement, how many students reached the objective(s), and how effective the teaching strategies actually were. Ko (2012) claimed that education has entered an era of lesson planning where the formal lesson plan is more often used to inform administrators of a teacher's curriculum coverage rather than used as a teaching tool during class. Ko (2012) remarked that the majority of in-service teachers mentally plan their lessons or use the box-style of lesson planning. Despite the strengths and weaknesses of lesson plans, two different studies have observed that the ultimate goal of a lesson plan is for the student to be able to work with the concept/material without the instructor present (DeFrece, 2010; Ko, 2012).

\section{Literature Review}

How does an educator go about writing a lesson plan and what does it include? The answer is complex and varies among educators (Ko, 2012). Estes, McDuffie, and Tate (2014) provided a lesson planning process with four phases: (a) goals aligned to assessments, standards, and necessary vocabulary; (b) topic progression including remediation and extension activities; (c) student perspectives including individual student needs; and (d) task selection including procedures, materials, and products. Krajcik, Codere, Dahsah, Bayer, and Mun (2014) provided a 10 step lesson planning process that is reflective as well as iterative (see Appendix A). Gershon (2013) said that instructional preparation should include planning for the progress of students by differentiating activities in advance. With so many different processes and formats of lesson plans available, a comprehensive list of the possible elements in a lesson plan has been compiled from the current research (see Appendix B). Wiggins and McTighe (2005) claimed there are two cardinal "sins" of planning to which many teachers fall prey. These include planning with a focus on activities and on coverage of material. Instead, they suggest an understanding-focused planning process that they call "backwards design" which is an objective-first planning method (Wiggins \& McTighe, 2005).

Estes, McDuffie, and Tate (2014) claimed that developing clear learning objectives is a critical first step in the lesson planning process. The idea of backwards planning begins with objective development, or what the teacher expects the student to be able to do at the conclusion of the lesson (Varlas, 2015). Ko (2012) claimed that teacher educators almost exclusively teach objective-first planning methods to pre-service teachers. However, only $15 \%$ of the pre-service teachers in their study identify objectives as an element of lesson planning. Ko (2012) reported that neither pre-service nor in-service teachers use an objective-first model of lesson planning for everyday teaching. In fact, objectives are actually rendered useless by pre-service teachers since there is rarely an emphasis on attending to student needs while lesson planning (Ko, 2012). DeFrece (2010) utilized objectives in a limited but meaningful way during the lesson planning process. DeFrece (2010) never defined more than two objectives per lesson, stated them in the order that they will be measured, or used icons throughout his actual lesson plans to represent those objectives, and he formally measured each objective only once. Hutchison and Woodward (2014) also suggested an objective-first model for implementing digital 
tools into daily lessons. Moss and Brookhart (2012) acknowledged the need for objectives in the lesson planning process with guidance in their book for writing learning targets, which are objectives that are no longer teacher-centered but learner-centered. These learning targets are meant to be written from the student's perspective in language that allows students to understand and reach the target much easier (Moss \& Brookhart, 2012).

Many districts require that lesson plans be submitted for each class to the teacher's supervising administrator (Spencer, 2013). Along with these mandates, many administrators add other instructional requirements that may seem limiting to teachers (Spencer, 2013). Spencer (2013) went on to say that, with some creative planning, a teacher does not need to lose their professional identity to such policies. California is home to one instance of these sorts of requirements. California has a specific policy that states that they not only require the presence of standards in each lesson plan, but also require the instructor to post the day's standards to be addressed in the classroom (Montgomery, 2012). Pre-service teachers are required, in many cases, to supply detailed lesson plans for each class they plan to teach (Ko, 2012). This fact is possibly the reason why pre-service teachers have a hard time in implementing, and therefore, reaching long-term learning goals (Ko, 2012). Moss and Brookhart (2012) noted that it is not uncommon for students, teachers, and administrators to work against one another in pursuit of learning achievement. They answer this realization with what they call The Learning Target Theory of Action which gives all three parties a common language and understanding with which to pursue achievement in the classroom (Moss \& Brookhart, 2012).

The purpose of this research study is to uncover the types of lesson plans teachers use during class and the way teachers use those lesson plans during class time. This information will provide insight into the utility of a lesson plan to inform future research in various areas of lesson planning: most useful planning process, format, district mandates in terms of lesson plans, etc.. There is a tendency in the current research to suggest that the best practices for lesson planning include a process with many time-consuming steps. These sorts of processes can potentially make the task of lesson planning so long that it is no longer useful during class. Therefore, this study aims to find out what in-service teachers are actually doing to see if it contradicts what current research says is best practices.

There is a gap in the current research on understanding a teacher's use of lesson plans within a classroom setting. There is recent research on pre-service teachers' use of lesson plans (Ko, 2012). However, there is no recent research on in-service teachers' use of lesson plans that takes into account recent educational trends, such as common core standards, universal design, inquiry based learning, etc.. Other research exists about specific lesson planning strategies, which help inform the practice of lesson planning, but do not include information on the practical use of lesson plans and the lesson planning process. Therefore, the following research questions are explored throughout the study:

1. What types of information/elements do in-service teachers include in their lesson plans?

2. How are in-service teachers using these lesson plans during class?

According to research, the process for planning a lesson includes a multitude of complex steps. When each day of teaching requires multiple lesson plans, the time necessary for planning far exceeds the amount of time spent in teaching. Therefore, it is the study's expectation that a lesson plan should be more practically useful if it requires less time than teaching the lesson. In addition, it is expected that in order to be easier to use during class, a lesson plan should include five or fewer elements. 


\section{Methods}

\section{Participants}

Participants in this study include in-service secondary teachers with at least one year of experience. Other factors, such as gender, age, years of experience, and subject area will be considered during the analysis, but will not be used as eligibility requirements. The survey will be sent to all teachers at one public high school in the northeast United States.

\section{Setting}

The school district of the high school is situated in a suburban area with the median income of approximately $\$ 44,000$ per year. The district serves a community of around 11,300 residents. The high school itself serves over 2,100 students in Grades 9-12. There are 164 full-time teachers in the faculty across 13 academic departments. The median years of experience for the full time teachers are in the interval of 11-15 years (see Appendix C). Turnover for teachers in this district is mostly attributed to retirement. Through the recent financial climate, teachers are only lost to attrition, and there are no teacher furloughs.

\section{Instruments}

Three instruments were used to collect data from participants: A survey, lesson plans used by the teachers in the high school, and a small set of interviews. The survey includes nine questions covering demographic information, opinions on lesson plan format, and personal use of lesson plans during class (see Appendix D).

After the nine questions are completed in the survey, participants have the option to upload a lesson plan they use. These lesson plans will be used to gain a better understanding of how lesson plan documents differ among teachers (see Appendix E). Teachers are asked by the administration to share some of their instructional materials with the entire faculty in an effort to promote collaboration and further development of best practices. This database of materials includes class resources, assessment tools, ideas, lesson plans, etc.. The lesson plans were collected from this database, in addition to the teacher submitted lesson plans from the survey. Lesson plans from both sources will be coded, so that trends in their contents may be uncovered.

At the end of the survey, participants will be asked if they are willing to participate in an interview with the researcher. If they are willing to be interviewed, they will be sent to a separate survey to enter their contact information. The researcher will interview only five participants who provide their contact information. If more than five participants are willing to be interviewed, five participants will be chosen at random from those who provide contact information (see Appendix F).

All three instruments needed to be coded to some extent. Two of the survey questions were open-ended, and thus, needed a coding protocol. Question 6 asked participants to list the elements the participant included in their lesson plans on a daily basis while Question 8 asked participants to list the elements they would include in their lesson plans if time and work were not factors. These questions were coded by counting the number of times each lesson plan element was mentioned in the responses. The lesson plans were coded in a similar fashion as the above survey questions by counting the number of times each lesson plan element was used in the lesson plans. The interviews were coded differently. Each question was coded by counting the number of times a phrase or element was mentioned for that particular question. The phrases and elements are unique to each question. Therefore, each question is coded independently of the others (see Appendix G). 
The survey tool and the interview questions had been reviewed and revised by a panel of experts. This panel of experts was diverse in the field of education including elementary, secondary, and higher education professionals as well as secondary level administration professionals. Together these experts represented 55 years of teaching experience. They were asked to review and provide feedback on the survey and interview questions in order to make informed revisions.

\section{Procedure}

The main survey included all three instruments in one: A nine survey questions, a place to upload their lesson plan, and a place to show interest in participating in an interview. The survey was made using the Qualtrics survey tool. The main survey was sent out via school email to all faculty members at the participating high school during summer break in the middle of July. The email included a link to the online survey. The survey was made available for two weeks.

\section{Findings}

The following findings describe the responses and contributions of the 15 teachers, six male and nine female, who responded to the survey email. The respondent experiences range was six to 34 years with the average of being 15.5 years.

Objectives showed up in various instruments as an essential component of lesson planning. During the interviews, all five participants mentioned objectives as a part of their lesson planning process. Half the lesson plans included objectives in their format. In the survey responses, two-thirds of participants noted that objectives were included in their daily lesson plans. In addition, two participants noted that objectives would be included if time were not a factor in the planning process. The question in the survey that asked participants to rank common lesson plan elements (title, objectives, standards, warm-up, assignments, materials, assessment, and questioning) showed that objectives had the rating of being most important of the eight elements with a mean score of 1.60. Ranking the eight elements from one to eight, "one" for most important and "eight" for least important, the closest rating to objectives in this question was "questioning" with a mean rating of 3.27.

The majority of teachers do not refer to a physical form of their lesson plan during the lesson for anything more than the order of events. This can be seen throughout multiple instruments. In the interviews, four of the five respondents noted that they did not refer to their lesson plan during class except to see what was next in their order of activities to be completed. The survey asked teachers to indicate how many times in a 41 minute class period they referred to their lesson plan. The average number of times was 1.57 . Three of the 15 participants indicated that they looked at it zero times in a class period while 12 of the 15 participants indicated that they looked at it anywhere from zero to one times in a class period.

The "order of events" can also be labeled as "procedures" in a lesson plan and this element kept showing up in the data as an essential element to lesson planning. Four of the five participants interviewed expressed that they developed their class procedures during the planning process. All four lesson plans included procedures as part of their format. According to the survey responses, $60 \%$ of the respondents included procedures as an element found in their lesson plans. One participant indicated that procedures would be included if time were not a factor in the planning process (see Table 1). 
Table 1

Percentages That Each Element Appeared Throughout the Surveys and Collected Lesson Plans.

\begin{tabular}{|c|c|c|c|}
\hline Element & $\begin{array}{l}\text { Included in daily lesson } \\
\text { planning (15 total) (\%) }\end{array}$ & $\begin{array}{l}\text { Would include if time were not } \\
\text { a factor (15 total) (\%) }\end{array}$ & $\begin{array}{l}\text { Included in collected lesson } \\
\text { plans (4 total) (\%) }\end{array}$ \\
\hline Level of difficulty & 6.67 & - & - \\
\hline Demonstration & 6.67 & - & - \\
\hline Assessment & 40.00 & 6.67 & 75.00 \\
\hline Warm-up & 60.00 & - & 75.00 \\
\hline Cool-down & 33.33 & - & 75.00 \\
\hline Class/subject & 6.67 & - & 75.00 \\
\hline Enrichment & 6.67 & - & - \\
\hline Evaluation & 13.33 & - & - \\
\hline Content & 13.33 & 13.33 & - \\
\hline Follow-up activities & - & 20.00 & - \\
\hline Application & 6.67 & - & - \\
\hline Materials & 66.67 & 13.33 & 25.00 \\
\hline Differentiation & 6.67 & 6.67 & - \\
\hline Objectives & 66.67 & 6.67 & 50.00 \\
\hline Script & 6.67 & - & - \\
\hline Topic & 13.33 & - & 50.00 \\
\hline Assignment & 33.33 & - & 25.00 \\
\hline Title & 6.67 & 6.67 & 50.00 \\
\hline Essential questions & 6.67 & - & - \\
\hline Time for activities & - & 6.67 & - \\
\hline Interdisciplinary & 6.67 & - & - \\
\hline Questioning & 13.33 & 26.67 & 25.00 \\
\hline Technology & 6.67 & 6.67 & - \\
\hline Standards & 26.67 & 20.00 & 25.00 \\
\hline Examples & 13.33 & 6.67 & - \\
\hline Procedures & 60.00 & 6.67 & 100.00 \\
\hline Expected issues & 6.67 & - & 25.00 \\
\hline Notes & 6.67 & - & - \\
\hline Overview & 6.67 & 6.67 & 50.00 \\
\hline Connect to objectives & - & 6.67 & - \\
\hline Teacher & - & - & 75.00 \\
\hline Broad goals & - & - & 25.00 \\
\hline Prerequisite skills & - & - & 50.00 \\
\hline Day/date & - & - & 25.00 \\
\hline Reflection & - & - & 25.00 \\
\hline Pre/post assessments & - & - & 25.00 \\
\hline
\end{tabular}

\section{Discussion}

The variety of formats and uses of lesson plans speak to the complexity of the teaching profession, including teaching styles, effectiveness, decision-making, and how those things relate to lesson planning itself. The current research and this study both indicate that it is rare to find two teachers who plan lessons the same way, produce the same sort of lesson plan, and/or use the lesson plan the same way during class. According to the in-service teachers in this study, the essential elements of a lesson plan are objectives, questions to ask, materials, and warm-up explanation. These four elements fulfill the expectation that teachers would utilize a lesson plan 
format with five or fewer elements. This fact makes the process of lesson planning much more efficient and maximizes the guidance the plan can provide during class, making the lesson plan as practical as possible.

Ko (2012) did a similar study to this one that investigated a pre-service teacher's views, process, and format of lesson planning. This study concluded that pre-service teachers were unlikely to use an objective-first lesson plan and process due to their student-teaching experiences. During these experiences, their cooperating teachers would focus primarily on the content that needed to be delivered, the activities that were best suited to deliver that content, and the instructional materials needed to complete those activities (Ko, 2012). Since Ko's study in 2012, the school district for this study has adopted the Charlotte Danielson framework for teacher evaluation and lesson planning, which is possible explanation for a faculty driven by objective-first planning.

\section{Limitations}

The limitations in this study include a low response rate from the teachers of the participating school district. This limitation can be explained a number of ways. The timing of survey distribution was at a time (summer vacation) when teachers were not checking their school email as often as other times of the year. Since there was no incentive offered to the teachers for participating, the idea of contributing to the body of research may not have been enough to persuade teachers to participate. This low response rate contributed to other limitations throughout the study:

1. A small amount of lesson plans were shared;

2. No statistical test was significant enough to include in the research;

3. No correlation coefficients were found to be strong enough to include either;

4. There is no effect size or statistical power to report for the collected data.

\section{Conclusions}

Despite these limitations, some of the conclusions that we were able to draw appear to be generalizable to the population of high school teachers in the United States. Our sample was diverse in that it represented many different state teaching certifications. Due to teachers holding multiple state certificates, there were 14 different certified teaching areas covered for those 15 participants and many of them were listed multiple times (see Appendix H). The samples did not diverse in the areas of race, socio-economic status, and available classroom resources.

There are a few interesting and unexpected responses throughout the surveys and interviews that are worth exploring. There is one participant who prints each lesson plan as notes for students, because they include all the material covered, examples with solutions, and further practice problems. Using a lesson plan in this way not only allows the teacher to use it as a road map during class, but it is a product for the students to look back on as well. Dual use of a lesson plan is the best practices in future research on the topic of lesson plan.

Another participant notes putting an agenda on the board for each class so that it is not necessary to look at the hard copy of the lesson plan during class and the students also get to use the agenda as a checklist of things to be completed. In recent years, some institutions have required teachers to not only post an agenda, but also clearly post the day's objectives, standards, etc. for students to see (Spencer, 2013). Moss and Brookhart (2012) supported a classroom in which students can clearly reference the day's learning targets that are written in such a way that students can easily understand and adhere to them during class. Another interesting proposition is that these posted resources could be considered a type lesson plan in itself. This proposition and the current 
research on the topic suggests a trend in education, but more research needs to be done to uncover how and in what ways the practice is useful for teachers and students.

Another teacher has transformed paper lesson plans into PowerPoint presentations. These presentations provide students with the content, examples, etc., while also providing students and the teacher with a sequence of events and other traditional lesson plan elements like objectives. The teacher also notes that every year it is important to revise these presentations and adapt them for the new students. This process is vastly different from the ones expressed from the other teachers and from the ones found in the current research. However, the concepts are not new. Future research will delve into lesson plans of varying forms such as class notes, PowerPoint presentations, on-board agendas, etc..

The current research predominately supports a lesson planning process that takes longer than the lesson itself and a lesson plan format that includes details of each lesson producing a document of three or more pages. In reviewing the literature, the researchers behind these well-respected and widely adopted processes put some sort of warnings for readers in their works. These warnings indicate that if these measures, steps, and details are not adhered to through the process of lesson planning, students simply will not learn (Cunningham, 2009; Moss, Brookhart, \& Long, 2011; Wiggins \& McTighe, 2005). However, Ko (2012) found that in-service teachers and student teachers are rarely able to utilize such processes. This study's survey uncovers the same results, showing that very few teachers do not produce the detailed lesson plans that the research supports. This discrepancy between research and reality is worth investigating as there is some sort of obstacles in the way of lesson planning using best practices, and the research suggests that student learning is the only victim. Therefore, the future research could explore topics, such as the optimal amount of time to plan quality lessons, what type of process produces better results, or even a way to find common ground among those in research and those in the classroom.

This study provides a look into what teachers are actually using in the classroom in terms of lesson planning. This information is vital in improving current educational practices and further informing educators who are implementing and developing best practices. Without this information, there is no starting point for further research, improving student outcomes, and educational change in the area of lesson planning. This can lead to various comparative studies, such as comparing the lesson planning processes and format for the following groups: elementary, middle, and high school level teachers; teachers of differing subjects within the same level of teaching; teachers with varying degrees of experience and educational background; teachers in different locations; and teachers with students of varying socio-economic status and classroom resources. Explorations into alternative methods of lesson planning could also be studied and compared to one another, such as backwards design, transforming plans into other forms, universal design, differentiated instruction, project-based learning, inquiry-based education, etc.

Higher education plays a large part in the process of lesson planning in primary and secondary environments, as institutions of higher education are responsible for developing and implementing teacher education programs that comply with state and national standards. According to Ko (2012), there was a disconnection between how pre-service teachers were trained to plan lessons and how in-service teachers actually planed lessons. This inconsistency is the cause for more research to answer some of the following questions:

1. Why do teachers not plan in the way they are trained?

2. Is there a different way more useful to train teachers?

3. Do in-service teachers need resources or support that they are not getting in order to plan using best practices? 
4. Will it be beneficial during teacher training to allow teachers to explore their own methods of lesson planning?

Therefore, the information provided by this study can act as a springboard for a whole body of research on the most practical and universal of teaching processes and lesson planning.

\section{References}

Al-Seghayer, K. (2014). A literature-based lesson. Perspectives, 22(3), 30-32.

Courey, S. J., Tappe, P., Siker, J., \& LePage, P. (2012). Improved lesson planning with universal design for learning (UDL). Teacher Education and Special Education, 36(1), 7-27. doi: 10.1177/0888406412446178

Crane, B., Towne, A., \& Crane-Seeber, J. P. (2013). The four boxes of gendered sexuality: A lesson plan for teaching about the history and effects of gendered sexuality. American Journal of Sexuality Education, 8, 274-305. doi: 10.1080/15546128.2013.854008

Cunningham, G. (2009). The new teacher's companion: Practical wisdom for succeeding in the classroom. Alexantria, VA: ASCD. Retrieved from http://www.ascd.org/publications/books/109051/chapters/Lesson-Plans-and-Unit-Plans@-The-Basisfor-Instruction.aspx

DeFrece, R. (2010). Planning for success: Optimizing your teaching. General Music Today, 24(1), 32-40. doi: $10.1177 / 1048371310368485$

Dunn, R., Craig, M., Favre, L., Markus, D., Pedota, P., Sookdeo, G., Stock, J., \& Terry, B. (2010). No light at the end of tunnel vision: Steps for improving lesson plans. The Clearing House, 85, 194-206. doi: 10:1080/00098650903507460

Estes, L. A., McDuffie, A. R., \& Tate, C. (2014). Lesson planning with the common core. The Mathematics Teacher, 108(3), 206-211.

Gershon, M. (2013). Classroom practice: Avoid a sinking feeling with perfect planning. The Times Educational Supplement, 5072, 34-38.

Goldston, M. J., Day, J. B., Sundberg, C., \& Dantzler, J. (2010). Psychometric analysis of a 5e learning cycle lesson plan assessment instrument. International Journal of Science and Mathematics Education, 8, 633-648.

Hutchison, A., \& Woodward, L. (2014). A planning cycle for integrating digital technology into literacy instruction. The Reading Teacher, 67(6), 455-464. doi: 10.1002/TRTR.1225

Ko, E. K. (2012). What is your objective?: Preservice teachers' views and practice of instructional planning. The International Journal of Learning, 18(7), 89-100.

Krajcik, J., Codere, S., Dahsah, C., Bayer, R., \& Mun, K. (2014). Planning instruction to meet the intent of the next generation science standards. Journal of Science Teacher Education, 25(2), 157-175. doi: 10.1007/s10972-014-9383-2

Kubilinskiene, S., \& Dagiene, V. (2010). Technology-based lesson plans: Preparation and description. Informatics in Education, 9(2), 217-228.

Leeper, A. (2014). Get charged up. Booklist, 11(5S), 8-13.

Lewis, K. (2015). Adventure awaits you and your students. Scholastic Scope, 63(9), 1-18.

Lyons, P. (1992). Thirty-five lesson formats: A sourcebook of instructional alternatives. Englwood Cliffs, N.J.: Educational Technology Publications.

Magyar, A. (2013). The successful classroom: Six ways to plan for the unexpected. New Teacher Advocate, 21(2), 12-13.

Milkova, S. (2014). Strategies for effective lesson planning. Center for Research on Learning and Teaching. Retrieved from http://www.crlt.umich.edu/gsis/p2_5

Mongomery, R. (2012). It serves a bigger purpose: The tension between professional identity and bureaucratic mandate in public education. English Teaching: Practice and Critique, 11(3), 45-58.

Moss, C. M., \& Brookhart, S. M. (2012). Learning targets: Helping student aim for understanding in today's lesson. Alexandria, V.A.: Association for Supervision and Curriculum Development (ASCD).

Moss, C. M., Brookhart, S. M., \& Long, B. A. (2011). Knowing your learning target. Educational Leadership, 68(6), 66-69.

Rodesiler, C. A., \& McGuire, J. M. (2015). Ideas in practice: Professional development to promote universal design for instruction. Journal of Developmental Education, 38(2), 24-31.

Royce, C. A. (2013). 3-2-1 blast off. Science and Children, 59(9), 18-23.

Shores, M. L., \& Smith, T. G. (2011). Designing and developing lesson plans for K-12 classrooms. Computers in the Schools, 28, 27-38. doi:10.1080/07380569.2011.551087

Spencer, J. T. (2013). Bad policy, bad practice. Phi Delta Kappan, 94(7), 72-73.

Varlas, L. (2015). Writing a master plan. Education Update, 57(4), 1-5. 
Warford, M. K., \& White, W. L. (2012). Reconnecting proficiency, literacy, and culture: From theory to practice. Foreign Language Annals, 45(3), 400-414. doi:10:111/j.1944-9720.2012.01200.x

Wiggins, G., \& McTighe, J. (2005). Understanding by design. Alexandria, V.A.: Association for Supervision and Curriculum Development (ASCD).

Williams, J, Evans, C., \& King, L. (2012). The impact of universal design for learning instruction on lesson planning. The International Journal of Learning, 18(4), 213-222.

\section{Appendix A}

Ten Step Process to Guide Teachers in Developing a Sequence of Lessons (Krajcik et al., 2014)

1. Select PEs that works together—a bundle—to promote proficiency in using the ideas expressed. Often, the bundle will include PEs from a single NGSS topic (see topic arrangement) or DCI (see DCI arrangement), but a bundle could draw in PEs from other topics or DCIs.

2. Inspect the PEs, clarification statements, and assessment boundaries to identify implications for instruction.

3. Examine DCI(s), science and engineering practices, and crosscutting concepts coded to the PEs to identify implications for instruction.

4. Look closely at the DCI(s) and PE(s). What understandings need to be developed? What content ideas will students need to know? What must students be able to do? Take into consideration prior PEs that serves as the foundation for cluster of PEs, the lessons will address.

5. Identify science and engineering practices that support instruction of the core ideas. Develop a coherent sequence of learning tasks that blend together various science and engineering practices with the core ideas and crosscutting concepts.

6. Develop lesson level PEs. Lesson level expectations guide lesson development to promote student learning. They build to the level of understanding intended in the bundle of PEs.

7. Determine the acceptable evidence for assessing lesson level performances, both formative and summative.

8. Select related Common Core Mathematics Standards (CCSS-M) and Common Core Literacy Standards (CCSS-L).

9. Carefully construct a storyline to help learners build sophisticated ideas from prior ideas, using evidence that builds to the understanding described in the PEs. Describe how the ideas will unfold. What do students need to be introduced to first? How would the ideas and practices develop over time?

10. Ask, “How do the task(s)/lesson(s) help students move towards an understanding of the PE(s)?”

\section{Appendix B}

List of possible lesson plan elements compiled from the following sources: Al-Seghayer (2014); Crane, Towne, and Crane-Seeber (2013); DeFrece (2010); Dunn et al. (2010); Estes, McDuffie, and Tate (2014); Goldston et al. (2010); Kubilinskiene and Dagiene (2010); Leeper (2014); Lewis (2015); Magyar (2013); Montgomery (2012); Royce (2013); Shores and Smith (2011); and Williams et al. (2012).

\section{Commas Separate Alternative Names for the Same Element}

Title

Objectives

Objective summary

Standards

Procedures

Teacher input

Guided practice 
Independent practice

Development

Application

Anticipatory set, starter, and warm-up

Exit slip, finisher, and cool-down

Assignment

Resources (include online), attachments

Materials

Questions to ask and/or address

Prior knowledge, prerequisites

Formative assessments

Summative assessments

Rubrics, assessment tools

Overview, summary, and preview

Duration

Extension activities

Remediation activities

Student barriers

Multiple means of presentation, engagement, and expression

Key skills

Vocabulary

Essential questions

Literature connections

Skills focus

Extra time activities

Appendix C

\section{Teacher Years of Experience of the Participating School District}

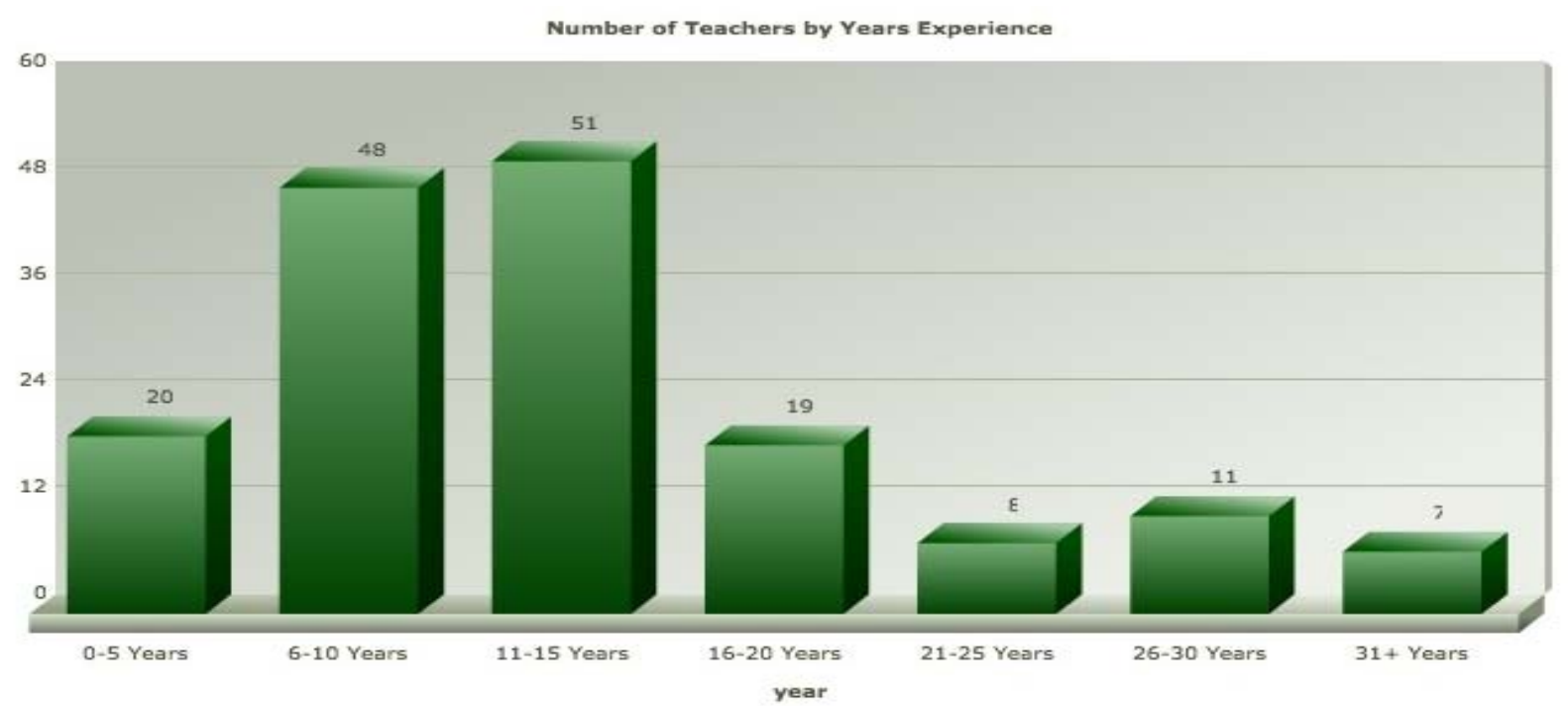




\section{Appendix D}

\section{Survey Used by Participants in This Study}

You are invited to be in a research study of how lesson plans are used by teachers during class. You were selected as a possible participant because you are an in-service teacher. Please read the following statement about the study and indicate below your willingness to participate in the remainder of the study. The purpose of the study is to uncover the types of lesson plans teachers use during class and use that information to develop a lesson plan format that will be most useful to teachers during class. Participation includes the completion of this survey and optional follow-up opportunities. At the end of the survey, you will have the option to upload a lesson plan you have used during class and also indicate your interest in participating in a short interview. There is minimal risk involved for participants as this study is only looking at the opinions and experiences of its participants. The only apparent risk is the interruption to your much needed summer vacation. However, your participation is entirely voluntary. The benefit to participants is in being part of a professional community which aims to inform policy makers, educational change, and the overall improvement of teaching practices. The responses you provide in this survey and any lesson plans you upload will be kept anonymous. If you choose to participate in the short interview, your responses will be kept completely confidential. You, as the participant, get to choose the extent to which you participate. The study includes three parts: the survey, uploaded lesson plans, and interviews. Please contact the researcher or the manager of research integrity at Lehigh University if you have questions or concerns about anything listed here.

Q1

1. I do not consent to participate in this study.

2. I may continue later after having my questions answered by one of the above parties.

Q2 Choose the gender with which you identify.

Male

Female

Q3 What is your age?

Q4 How many years of teaching experience do you have?

Q5 What subject areas are you certified to teach? You may list as many as necessary.

Q6 Thinking about the lesson plan format you use on a day to day basis, what elements do you include in those lesson plans? "Elements" are the headings your lesson plan may include or just the general information you include in your lesson plan. A few examples are title, standards, objectives, materials, etc. List as many elements as you normally include.

Q7 There are some common lesson plan elements listed below. Please put them in order of their importance for use during class time. " 1 ” is the most important and "8” is least important to a lesson plan format for use during class.

Title

Objectives

Standards

Starter activity/warm-up activity

Follow-up assignments

Materials

Assessment information

Questions to ask students

Q8 If time and amount of work included was not a factor, what elements would the ideal lesson plan format include in order to be the most useful during class time? "Elements” are the headings your lesson plan may include or just the general information 
you include in your lesson plan. A few examples are: title, standards, objectives, materials, etc.. List as many elements as you normally include.

Q9 How many times in a 41 minute class period do you refer to your lesson plan? Please provide a number greater than or equal to 0 .

\section{Appendix E}

\section{Questions in the Survey Asking Participants to Upload a Lesson Plan if They Are Willing}

Q10 Would you like to upload a lesson plan you have used? This is voluntary and separate from the survey questions. Therefore, your survey responses will still be recorded if you respond "No" to this question.

Yes

No

Q11 Upload your lesson plan here. Before uploading, make sure to remove any text that may have your name on it in order to preserve your anonymity.

\section{Appendix F}

Survey Questions Offering Participants the Opportunity to Participate in an Interview and the Questions That Will be Asked During the Interview

1. Survey questions offering the interview opportunity:

Q12 Would you like to participate in a short interview with the researcher? This may be in person or over the phone, whatever is most convenient for you. This is voluntary and separate from the survey questions. Therefore, your survey responses will still be recorded if you respond "No" to this question.

Yes

No

Q12 First and last name

Q13 Email address you check most frequently. It will only be used to contact you about the interview if necessary.

Q14 Daytime phone number

2. Interview questions for the five randomly chosen participants:

Q15 What department or departments do you teach in at the high school?

Q16 Can you describe the way you use your lesson plan during class?

Q17 What are the steps you take during the planning process to produce the plan you use during class?

Q18 How would you describe the difference between writing a lesson plan for use during class and writing a lesson plan for an administrator to follow during a formal observation?

\section{Appendix G}

\section{Coding Categories for Each Instrument}

1. Survey questions-Each element listed in the responses is listed below with the number of times it appeared next to it. There were a total of 15 survey responses coded.

(a) Thinking about the lesson plan format you use on a day-to-day basis, what elements do you include in those lesson plans? "Elements" are the headings your lesson plan may include or just the general information you include in your lesson plan. A few examples are title, standards, objectives, materials, etc.. List as many elements as you normally include.

Level of difficulty-1 


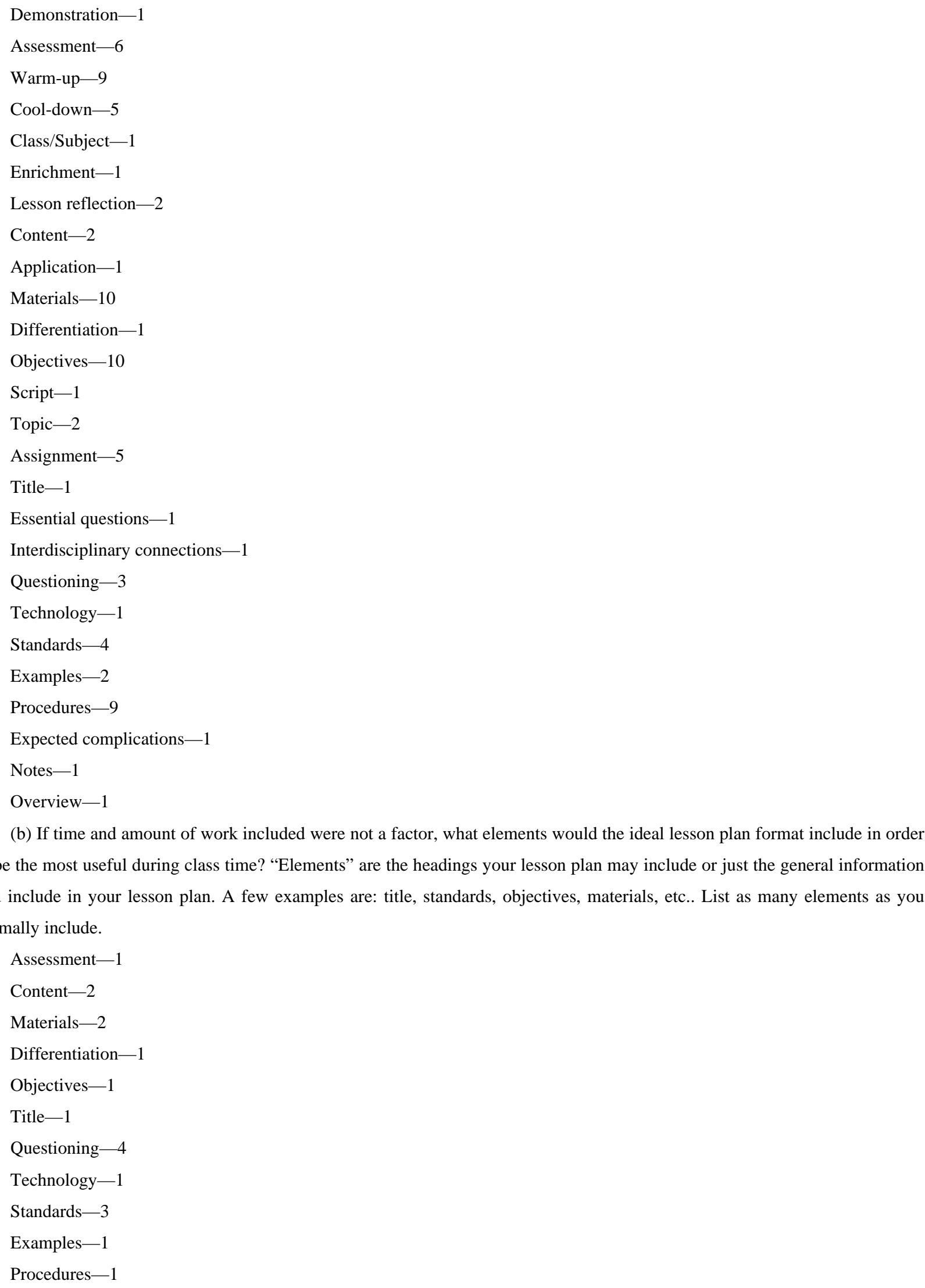


Overview-1

Follow-up activities-3

Time for activities-1

Connection to objectives-1

2. Lesson plans-Each element listed in the lesson plans is listed below with the number of times it appeared next to it. There were a total of four lesson plans coded.

Topic-2

Teacher-3

Class/Subject-3

Overview-2

Goals-1

Objectives-2

Standards-1

Assessment-3

Procedures-4

Warm-up-3

Wrap-up-3

Questions-1

Anticipated issues-1

Prerequisite skills-2

Materials-1

Date/Day-1

Reflection-1

Assignments-1

Title -2

Pre/Post assessment-1

3. Interviews-Each question is listed with the phrases/elements listed below and the number of times it appeared next to it. There were a total of five interviews coded:

(a) Can you describe the way you use your lesson plan during class?

I do not refer to it-4

I referred to it earlier in my career-3

I use it mentally-1

I refer to it occasionally for order of events-4

(b)What are the steps you take during the planning process to produce the plan you use during class? I consider...

Content-1

Time-1

Develop interactive/creative activities-3

Objectives-5

Assessments-2

Assignments-1

What students already know-2 
What I need to clarify-1

Procedures-3

My audience-2

(c) How would you describe the difference between writing a lesson plan for use during class and writing a lesson plan for an administrator to follow during a formal observation?

More specific-3

Connected to standards - 2

More time available-2

Include district mandate- 1

Include objectives—2

Include questioning-1

\section{Appendix H}

Table 2

List of Certifications Held by Study Participants

\begin{tabular}{ll}
\hline State certification & Number of participants certified in that area \\
\hline Biology & 3 \\
Business & 1 \\
Chemistry & 2 \\
Curriculum \& instruction supervisor & 1 \\
English & 3 \\
Environmental science & 1 \\
Family and consumer science & 2 \\
Mathematics & 6 \\
Physics & 2 \\
Principal & 1 \\
Social studies & 2 \\
Special education & 1 \\
World language (two languages) & 2 \\
\hline
\end{tabular}

